\title{
A Product Life Cycle Cost Concept Model to Solve Supplier Selection Problems in the Supply Chain Management
}

\author{
Tao Yu-Jwo ${ }^{1}$, Lin Yi- Shyuan ${ }^{1}$ Lee Hsuan-Shih ${ }^{2}$, Tu Chang-Shu ${ }^{3, *}$
}

1. Graduate Institute of Technological \& Vocational Education, National Taipei University of Technology,1, Sec. 3, Zhongxiao E. Rd., Taipei 10608 Taiwan, R.O.C. ta794260@gmail.com (Y.-J.T.);yishyuan@ntut.edu.tw (Y.-S. L)

2 Department of Shipping and Transportation Management, National Taiwan Ocean University, Pei-Ning Road, Keelung 202, Taiwan, R.O.C; No. 2, Pei-Ning Road, Keelung City 202301, Taiwan; hslee@email.ntou.edu.tw (H.-S.L.)

${ }^{3}$ Department of Information Management, Chang Gung University, No .259, WenHwa 1st Road, KweiShan,Taoyuan City 33302, Taiwan; long.tree@msa.hinet.net (C.-S.T.)

* Correspondence: long.tree@msa.hinet.net; Tel: +886927351833

\begin{abstract}
Today's purchasing companies demand an advanced buyer equal of enactment from their supplier while the two parties maintain a respectful connection. Although the supplier selection (SC) product life cycle cost (SCPLCC) is an important consideration among corporations, SCPLCC problem has become associated with deciding how one supplier should be selected from possible alternatives. In this study, we applied two types of goal programming, multiobjective linear programming and revised multichoice goal programming to develop a PLCC-based concept to solve the SCPLCC problem and construct a decision-making tool for application to a case of supply chain management in a Taiwanese light-emitting diode company in the high-tech industry. Our study main contribution Company managers can easily use the two approaches of the SCPLCC model with different parameters to solve SCPLCC model problems. Finally, we comparing five models found RMCGP with weighted linear goal programming had an adequate effect for application to the PLCC concept for high-technology comapny; this cloud make company decision-makers focus on low PLCC and select better supplier.
\end{abstract}

Keywords: supplier selection; geometric averaging-weighting; penalty weighting; multiobjective linear programming; revised multichoice goal programming. 


\section{Introduction}

Due to the globalization of commercial markets and the improvements in information technology, a well-made supply chain management (SCM) system is regarded as an important tool for gaining competitive advantage [1, 2]. In higher levels of the supply chain, supplier selection (SC) continues to be an crucial component in manufacturing procurement and, a major activity of professionals in the industry [3,4,5]. With the beginning of globalization, managing SC actions has turned into more multifaceted. SCM is an essential element of most businesses and is critical to corporation achievement and customer satisfaction. A supply chains (SCs) represents the pathways between suppliers and buyers (customers or consumers) [6].

In sum, for an industrial company, the primary goal is to make the correct product, for the correct customer, in the correct amount, at the correct time. Today's purchasing companies demand an advanced buyer equal of enactment from their supplier while the two parties maintain a respectful relationship. Although the SC product life cycle cost (SCPLCC) is an important consideration among corporations, the literature on this topic is limited. SCPLCC has become associated with deciding how one supplier should be selected from possible alternatives.

Therefore, optimization of the supplier base is a must for identifying high performing suppliers in supply chains. The SCPLCC problem-solving approach has been discussed for difficult problems in the literature for the following reasons:

(1) Attempts to incorporate information vagueness into the SCPLCC problem are scarce in the literature. The multiobjective linear programming (MOLP) model can account for the variation or imprecision of a decision maker's (DM's) aspiration level (i.e., the intermediate control variables) created thus producing a more assured key point for DM policy [7]. In our study, a fuzzy MOLP model and revised multi-choice goal programming (RMCGP) model were used to close the literature's gap. RMCGP with weighted linear goal programming had an adequate effect for application to the PLCC concept for high-technology company.

(2) We extended the work of Amid et al. [7], and used Wang's [5] study to handle the product life cycle cost (PLCC) problem, and we cited and modified the auto parts manufacturer' example data set from Kumar et al. [8] to solve the SCPLCC problem.

(3) Our study advantages by using MOLP and RMGCP SCPLCC models that incorporated geometric averaging-weighting to solve the SCPLCC model problem, the DM can understand the differences between giving or not giving all the objectives and constraints in the SC decision equal importance [9]. Our SCPLCC model can help DMs determine the appropriate prioritization of suppler and allow purchasing managers to manage SC performance on the basis of minimizing net cost, rejection, late delivery, and PLCC goals. Our study main contribution Company managers can easily use the two approaches of the SCPLCC model with different parameters to solve SCPLCC model problems [10].

The paper is organized as follows: First, we review the literature on the quantitative techniques of the SC decision in Section 2. In Section 3, the explanation formation and solution of the SCPLCC problems achieved by using the two approaches are presented. In Section 4 presents the problem-solving process of the two goal programming (GP) approaches based on the modified auto parts manufacturer' example data set [8] for solving SCPLCC problems to demonstrate the process, we adopted it to a light-emitting diode (LED) company in Taiwan. In Section 5, conclusions are drawn regarding the advantages of SC with these two approaches in real business-world applications.

\section{Literature review}

The criteria for SC and supplier rating have been a focus of research since the 1960s. Dickson [11] identified a list of at least 50 distinct factors presented by various authors in the literature that are meaningful in SC. Different methods have been used for SC, such as linear weighting methods, mathematical programming models [e.g. linear programming (LP), GP]. Goal Programming (GP) is a technique in the field of multi-criteria decision making (MCDM). GP is to 
minimize the unwanted deviations of the objective values determined by the decision-maker to reach an acceptable resolution.

In the present study, we classified research on SC into two major categories [e.g., Qualitative factor approach and integrated factor approach] and several representative publications are listed in Table 1. Methodical models for SC have comprised diverse methods from simple weighted scoring methods to compound mathematical programming, and the best researchers have utilized multiple elements in their selection criteria [12]. These methods often include a large degree of subjectivity in the DM process.

Table 1. Summary of the recent studies using mathematical programming models for supply chain

\begin{tabular}{|c|c|c|c|c|c|c|c|c|c|}
\hline $\begin{array}{l}\text { Author(s)/yea } \\
\text { r }\end{array}$ & Category & $\begin{array}{l}\text { Suppl } \\
\mathrm{y} \\
\text { chain }\end{array}$ & Methods & $\begin{array}{l}\text { Cos } \\
t\end{array}$ & $\begin{array}{l}\text { Rejectio } \\
\mathrm{n}\end{array}$ & $\begin{array}{l}\text { Deliver } \\
\mathrm{s}\end{array}$ & $\begin{array}{l}\text { PLC } \\
\text { C }\end{array}$ & $\begin{array}{l}\text { Capacit } \\
\mathrm{y}\end{array}$ & $\begin{array}{l}\text { Budge } \\
t\end{array}$ \\
\hline $\begin{array}{l}\text { MO' Ath et al. } \\
\text { (2017) [13] }\end{array}$ & Integrated & $\checkmark$ & WGP,LP & & & & $\checkmark$ & & $\checkmark$ \\
\hline $\begin{array}{l}\text { Umarusman } \\
(2018)[14]\end{array}$ & $\begin{array}{l}\text { Qualitativ } \\
\mathrm{e}\end{array}$ & $\checkmark$ & criterion & $\checkmark$ & $\checkmark$ & $\checkmark$ & & & \\
\hline $\begin{array}{l}\text { Budzinski et } \\
\text { al. (2019) [15] }\end{array}$ & Integrated & $\checkmark$ & & & & & $\checkmark$ & & \\
\hline $\begin{array}{l}\text { Ojo et al. } \\
(2020)[16]\end{array}$ & $\begin{array}{l}\text { Qualitativ } \\
\mathrm{e}\end{array}$ & $\checkmark$ & GP & & & & & & $\checkmark$ \\
\hline $\begin{array}{l}\text { Hocine et al. } \\
\text { (2020) [17] }\end{array}$ & Integrated & $\checkmark$ & WA-FMCGP & $\checkmark$ & & & & & $\checkmark$ \\
\hline $\begin{array}{l}\text { Hardy et al. } \\
(2020)[18]\end{array}$ & $\begin{array}{l}\text { Qualitativ } \\
\mathrm{e}\end{array}$ & $\checkmark$ & & & & & & & \\
\hline $\begin{array}{l}\text { AI-Huaain et } \\
\text { al. (2020) [19] }\end{array}$ & $\begin{array}{l}\text { Qualitativ } \\
\mathrm{e}\end{array}$ & $\checkmark$ & GP & $\checkmark$ & & & & $\checkmark$ & $\checkmark$ \\
\hline $\begin{array}{l}\text { Bibhas and } \\
\text { Sushil }(2020) \\
{[20]}\end{array}$ & $\begin{array}{l}\text { Qualitativ } \\
\mathrm{e}\end{array}$ & $\checkmark$ & $\begin{array}{l}\text { Game } \\
\text { Theoretic }\end{array}$ & $\checkmark$ & & & & & $\checkmark$ \\
\hline $\begin{array}{l}\text { Biswarup and } \\
\text { Bibhas (2021) } \\
{[21]}\end{array}$ & $\begin{array}{l}\text { Qualitativ } \\
\mathrm{e}\end{array}$ & $\checkmark$ & $\begin{array}{l}\text { Game } \\
\text { Theoretic }\end{array}$ & $\checkmark$ & $\checkmark$ & & & & $\checkmark$ \\
\hline $\begin{array}{l}\text { Bahareh et al. } \\
\text { (2021) [22] }\end{array}$ & $\begin{array}{l}\text { Qualitativ } \\
\mathrm{e}\end{array}$ & $\checkmark$ & FGP & & $\checkmark$ & & & & \\
\hline $\begin{array}{l}\text { Nasr et al. } \\
(2021) \text { [23] }\end{array}$ & $\begin{array}{l}\text { Qualitativ } \\
\mathrm{e}\end{array}$ & $\checkmark$ & FGP & $\checkmark$ & & $\checkmark$ & & & \\
\hline $\begin{array}{l}\text { Mabrouk } \\
(2021)[24]\end{array}$ & $\begin{array}{l}\text { Qualitativ } \\
\mathrm{e}\end{array}$ & $\checkmark$ & Fuzzy set & $\checkmark$ & & $\checkmark$ & & & \\
\hline
\end{tabular}


This study $\quad$ Integrated $\quad \checkmark \quad$ MOLP,RMCG

$\mathrm{P}$

The incorporation of data fuzziness in SCPLCC has not been prominent in the literature. Kumar et al. [24] presented a fuzzy goal programming models to minimize the total tolerable weighted variations of variables. In the present study, we first attempted to use two fuzzy programming approaches to close this gap in knowledge.

\section{Methods}

Zimmermann [25] used the approach of Bellman and Zadeh [26] to solve a fuzzy linear programming problem and demonstrated that an LP problem with a fuzzy goal and fuzzy restrictions might be reformulated such that it can be solved as a conventional LP problem. Indices, decision variables, and parameters are accounted for in the construction of a multiobjective LP model in accordance with a set of assumptions. The enriched multiobjective LP model is expressed as follows:

Assumptions

(i) Only one item is purchased from one supplier.

(ii) Quantity discounts are not considered.

(iii) The suppliers do not have shortages of the item.

(iv) The lead time and demand of the item are constant and known with confidence. Sets of indices, parameters and decision variables for the SCPLCC model are defined in Table 2.

Table 2. Terminology [fuzzy parameters are indicated by a tilde ( )].

\begin{tabular}{cl}
\hline \multicolumn{2}{l}{ Index } \\
\hline $\mathrm{i}$ & key index for supplier, for all $\mathrm{i}=1,2 \ldots \mathrm{n}$ \\
\hline $\mathrm{j}$ & key index for objectives function, for all $\mathrm{j}=1,2 \ldots \quad \mathrm{J}$ \\
\hline $\mathrm{k}$ & key index for constraints, for all $\mathrm{k}=1,2 \ldots \quad \mathrm{K}$ \\
\hline \multicolumn{2}{|c}{ Decision variable } \\
\hline$x_{\mathrm{i}}$ & Order quantity given to the supplier $\mathrm{i}$ \\
\hline \multicolumn{2}{l}{ Parameters } \\
\hline$\widetilde{D}$ & Aggregate demand of the item over a fixed planning period \\
\hline $\mathrm{n}$ & Number of suppliers competing for selection \\
\hline $\mathrm{p}_{\mathrm{i}}$ & Price of a unit item of ordered quantity xi to supplier $\mathrm{i}$ \\
\hline $\mathrm{R}_{\mathrm{i}}$ & Percentage of the rejected units delivered by supplier $\mathrm{i}$ \\
\hline $\mathrm{L}_{\mathrm{i}}$ & Percentage of the units delivered late by supplier $\mathrm{i}$ \\
\hline $\mathrm{C}_{\mathrm{i}}$ & PLCC ordered quantity xi to supplier $\mathrm{i}$ \\
\hline$\sim$ & $\quad$ Upper limit of the quantity available for supplier $\mathrm{i}$ \\
\hline $\mathrm{U}_{\mathrm{i}}$ & \\
\hline$r_{\mathrm{i}}$ & Vendor rating value for supplier $\mathrm{i}$ \\
\hline $\mathrm{P}$ & Least total purchasing value that a vendor can have \\
\hline $\mathrm{f}_{\mathrm{i}}$ & Supplier quota flexibility for supplier $\mathrm{i}$ \\
\hline $\mathrm{F}$ & Least value of flexibility in supply quota that a supplier should have \\
\hline $\mathrm{B}_{\mathrm{i}}$ & Budget constraint allocated to each supplier \\
\hline
\end{tabular}

Model: SCPLCC problem.

We can formulate the multiobjective SCPLCC problem with four fuzzy objectives and fuzzy crisp constraints as follows:

Minimize: $\quad \mathrm{Z}_{1} \cong \sum_{i=1}^{n} \mathrm{P}_{\mathrm{i}} x_{\mathrm{i}}$

Minimize $\quad \mathrm{Z}_{2} \cong \sum_{i=1}^{n} \mathrm{R}_{\mathrm{i}} x_{\mathrm{i}}$ 
Minimize $\quad Z_{3} \cong \sum_{i=1}^{n} \mathrm{~L}_{\mathrm{i}} x_{\mathrm{i}}$

Minimize $\quad \mathrm{Z}_{4} \cong \sum_{i=1}^{n} \mathrm{C}_{\mathrm{i}} x_{\mathrm{i}}$

Then, we can subject the problem to the following constraints:

$\sum_{i=1}^{n} x_{\mathrm{i}} \geq \tilde{\mathrm{D}} \quad$ (aggregate demand constraint)

$x_{\mathrm{i}} \leq \tilde{\mathrm{U}}_{\mathrm{i}} \quad \forall \mathrm{i} ; \mathrm{i}=1,2, \ldots \mathrm{n}$ (capacity constraint)

$\sum_{i=1}^{n} r_{i}\left(x_{i}\right) \geq \mathrm{P}$

$\sum_{i=1}^{n} f_{i}\left(x_{i}\right) \leq \mathrm{F}$

$\mathrm{P}_{\mathrm{i}} x_{\mathrm{i}} \leq \mathrm{B}_{\mathrm{i}}, \quad \mathrm{i}=1,2, \ldots \mathrm{n}$ (budget constraint)

$x_{i} \geq 0, i=1,2, \ldots n$ (non-negativity constraint)

This model has four main fuzzy objectives goals: minimization of total net cost; minimization of reject items, minimization of net late-delivered items, and the supplier's realization of the PLCC. The aggregate demand constraint ensures that the required quantity of supplied product items over a fixed planning period is satisfied. The supplier product capacity constraint limits supply on the basis of uncertain aggregate demand being set at $10 \%$ of the deterministic model. The budget constraint means that no one supplier can spend more than the budgeted amount of money allocated to it. Lastly, the nonnegativity constraint prohibits negative orders. Generally, the tilde symbol $(\sim)$ indicates that the situation is fuzzy, and in this model, both the objective functions and demand constraints were fuzzy parameters [9].

The fuzzy decision can be either symmetric or asymmetric depending on whether the weights are equal or unequal and on the objectives and restrictions $[9,25]$. This problem is characterized by the following membership function (MF):

$$
\mu_{d}(x)=\min \left(\mu_{g}(x), \mu_{c}(x)\right) \text {. }
$$

A general linear MOLP model for supplier selection with minimization $\left(Z_{1}, Z_{2}, Z_{3}, Z_{4}\right)$ and maximization of objective function $\left(Z_{2}\right)$ fuzzy and crisp constraints is expressed as follows [9]:

$Z_{1}=Z_{3}=Z_{4}=\sum_{i=1}^{n} c_{k i} x_{i}, \quad k=1,2,3,4 \quad Z_{2}=\sum_{i=1}^{n} c_{t i} x_{i}, \quad t=2$

s.t. $\sum_{i=1}^{n} a_{r i} x_{i} \geq d_{r}, r=1,2, \ldots m$ for fuzzy restrictions (capacity constraint $1,2,3,4$ )

$\sum_{i=1}^{n} b_{s i} x_{i} \geq d_{s}, \quad s=1,2, \ldots m$ for crisp restrictions (budget constraint $1,2,3,4$ )

$x_{i} \geq 0, \mathrm{i}=1,2, \ldots n$.

The treatment of objectives and restrictions in fuzzy LP is the same because they are defined through an individual MF. In Figure 1, the fuzzy objective functions and constraints of the SCPLCC problem are presented.

The membership function $\left(Z_{k}\right)$ and maximization goals $\left(Z_{l}\right)$ are given as follows: 


$$
\mu_{z k}(x)=\left\{\begin{array}{cl}
1 & \text { for } \quad Z_{k} \leq Z_{k}^{-} \\
f_{\mu_{z k}=\frac{\left(Z_{k}^{+}-Z_{k}(x)\right)}{\left(Z_{k}^{+}-Z_{k}^{-}\right)}} & \text {for } Z_{k}^{-} \leq Z_{k}(x) \leq Z_{k}^{+} \\
0 & \text { for } \quad Z_{k} \leq Z_{k}^{+}
\end{array}\right.
$$

$(k=1,2 \ldots p)$

$$
\mu_{z l}(x)=\left\{\begin{array}{cl}
1 & \text { for } \quad Z_{l} \geq Z_{l}^{+} \\
f_{\mu_{z l}=\frac{\left(Z_{l}(x)-Z_{l}^{-}\right)}{\left(Z_{l}^{+}-Z_{l}^{-}\right)}} & \text {for } Z_{l}^{-} \leq Z_{l}(x) \leq Z_{l}^{+} \\
0 & \text { for } \quad Z_{l} \leq Z_{l}^{-} \\
(l=p+1, \mathrm{p}+2 \ldots q) &
\end{array}\right.
$$

where $Z_{k}^{-}$and $Z_{l}^{+}$can be obtained through solving the multiobjective problem as a single objective using only one objective each time, $Z_{k}^{+}$is the maximum value (worst solution) of the negative objective $Z_{k}^{-}$and $Z_{l}^{-}$is the minimum value (worst solution) of the positive objective function $Z_{l}^{+}[8,27,28]$.

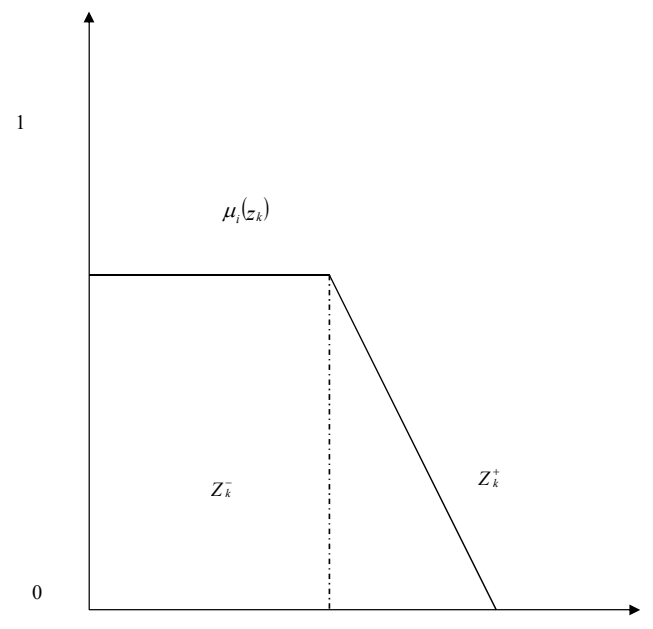

(a)

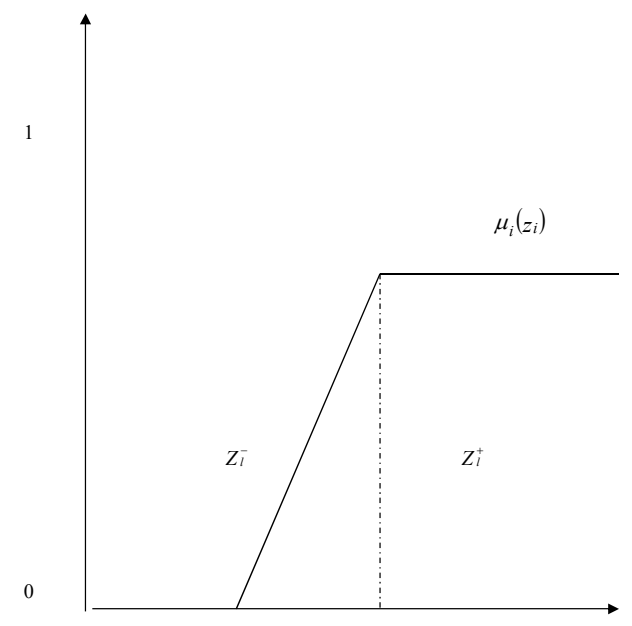

(b)

Figure 1. Objective function as a fuzzy number. (a) minimum $Z_{k}$ and (b) maximum $Z_{l}$.

\subsection{Solution to the SCPLCC Problem by using the Weighted Additive Approach}

This section specifies the convex (weighted additive; WA) model that enables DMs to select different weights for various purposes.

When solving the SCPLCC problem model, the weights of the membership functions of goals (objectives) and constraints are calculated according to a supertransitive approximation; thus, these weights are assigned separately. In these 
equations, $\alpha_{j}$ is the weighting coefficient that indicates the relative importance of the fuzzy goals and fuzzy restrictions.

The following crisp simplex objective programming function is the same as that of the fuzzy model.

$$
\begin{aligned}
& \operatorname{Max} \sum_{j=1}^{S} \alpha_{j} \lambda^{*} \\
& \lambda_{j} \leq \mu_{z j}(x) j=1,2, \ldots q, \text { for all objective functions } \\
& \gamma_{r} \leq \mu_{h r}(x) \quad r=1,2, \ldots h, \text { for all constraints } \\
& g_{m}(x) \leq b_{m}, \quad m=1, \ldots p, \\
& \lambda \in[0.1] \\
& \sum_{j=1}^{s} \alpha_{j}=1, \quad \alpha, 0, \\
& x_{i} \geq 0, \quad i=1,2, \ldots n .
\end{aligned}
$$

See Amid et al. [7] for a more detailed discussion of this model.

\subsubsection{Use Lin's Weighted Max-Min Approach}

Lin [29] suggested and proofed a weighted max-min approach that can catch an ideal resolution within a feasible area such that the ratio of the achievement level is as approximates equals to the ratio of the weight as possible. He highlighted that the WA model of Tiwari et al. [30] gives objectives of heavy weight relatively greater achievement values. However, the proportion of the achievement levels is not essentially the same as that of the objective weights [8,29]. Thus, for the solution of the SCPLCC problem model, the equations for Lin's weighted max-min model can be expressed as follows [8]:

$\operatorname{Max} \lambda$

Subject to

$w_{j} \lambda \leq \mu_{z j}(x) \quad j=1,2, \ldots q, \quad$ for all objection functions

$\gamma_{r} \leq \mu_{h r}(x) \quad r=1,2, \ldots h, \quad$ for all constraints

$g_{m}(x) \leq b_{m}, \quad m=1, \ldots p$,

$\lambda \in[0.1]$

$\sum_{j=1}^{s} \alpha_{j}=1, \quad \alpha_{j} \geq 0$,

$x_{i} \geq 0, \quad i=1,2, \ldots n$. 
See Amid et al. [8] for more detailed on this model.

\subsection{Revised MCGP Approach to Solving the SCPLCC Problem}

To address this SCPLCC problem issue, we used the revised MCGP `also known as the (RMCGP)) achievement function (AF) model developed by Chang [31], and the two RMCGP AF models are presented as follows:

1. RMCGP AF model -type I is used in the case of "more $\overline{\bar{F}}_{\bar{\tau}}$ is better" (i.e., achievement is the upper bound):

Minimize $\quad \sum_{i=1}^{n}\left[w_{i}\left(d_{i}^{+}+d_{i}^{-}\right)+\alpha_{i}\left(e_{i}^{+}+e_{i}^{-}\right)\right]$

Subject to

$$
\begin{aligned}
& f_{i}(X) b_{i}-d_{i}^{+}+d_{i}^{-}=b_{i} y_{i} \quad i=1,2, \ldots n, \\
& y_{i}-e_{i}^{+}+e_{i}^{-}=g_{i, \max } \quad i=1,2, \ldots n, \\
& g_{i, \min \leq} y_{i} \leq g_{i, \max } \\
& d_{i}^{+}, d_{i}^{-}, e_{i}^{+}, e_{i}^{-} \geq 0, \quad i=1,2, \ldots n,
\end{aligned}
$$

$X \in F$ where $F$ is a feasible set and $X$ is unrestricted in sign.

Note that $b_{i} \in\{0,1\}$ is a control variable attached to $\left|f_{i}(X)-y_{i}\right|$, which can be either achieved or released in Equation (27). In terms of real conditions, $b_{i}$ is subject to some constraints in guiding the relationships between the goals included in the SCPLCC model's problem.

2. RMCGP AF model -type II is used in the case of "less is better" (i.e., achievement is the lower bound):

Minimize $\quad \sum_{i=1}^{n}\left[w_{i}\left(d_{i}^{+}+d_{i}^{-}\right)+\alpha_{i}\left(e_{i}^{+}+e_{i}^{-}\right)\right]$

Subject to

$$
\begin{gathered}
f_{i}(X) b_{i}-d_{i}^{+}+d_{i}^{-}=b_{i} y_{i} \quad i=1,2, \ldots n, \\
y_{i}-e_{i}^{+}+e_{i}^{-}=g_{i, \min } \quad i=1,2, \ldots n, \\
g_{i, \min \leq} y_{i} \leq g_{i, \max } \\
d_{i}^{+}, d_{i}^{-}, e_{i}^{+}, e_{i}^{-} \geq 0, i=1,2, \ldots n,
\end{gathered}
$$

$X \in F$ where $F$ is a feasible set and $X$ is unrestricted in sign.

All variables use the definitions given in case I of the RMCGP AF model. All mixed-integer terms in Equations (27) and (29) can easily be linearized using the linearization method developed by Chang [31]. For example as presented in Equations (27), (29) and (30), no selection limitations exit for a single goal, but some dependent relationships between goals do exist. Thus, we can add the auxiliary constraint $b_{i} \leq b_{i+1}+b_{i+2}$ to the RMCGP AF model, where $b_{i}, b_{i+1}$ and $b_{i+2}$ are binary variables. Therefore, $b_{i+1}$ or $b_{i+2}$ must equal 1 if $b_{i}=1$. This means that if goal 1 has been accomplished, then either goal 2 or goal 3 must have also been 
accomplished Chang [39] presented a case regarding the managerial implications of these restrictions.

\subsection{SCPLCC Problem-Solving Process}

A comprehensive solution to the SCPLCC problem can be obtained to complete the following steps:

Step 1: Construction the SCPLCC problem model.

Step 2: Solve this MOLP problem with geometric averaging-weighting and obtain the value of the four objectives goals. This value is the min. (i.e., lower) and max. (i.e., upper) bounds of the ideal value of the four objective goals.

Step 3: Replicate the procedure for the residual objectives individually. Define the lower and upper bounds of the optimal values for each of the objectives matching to the set of restraints.

Step 4: Process these values as the lower and upper bounds of the ideal values for crisp construction of the SCPLCC problem.

Step 5: After steps 2, 3, and 4, for each objective function, find a lower bound and an upper bound matching the established resolutions for each objective goal. Let $Z_{\bar{j}}^{-}$and $Z_{j}^{+}$denote the lower and upper bounds for the $j$ th objective goal $\left(Z_{j}\right)[8]$.

Step 6: For the objective functions find the MF in relation to Equations (11) and (12).

Step 7: Perform geometric averaging-weighting for the criteria

Step 8: Express and solve the corresponding crisp geometric averaging WA model for the SCPLCC problems in relation to Equations (13) - (19).

Step 9:Express and solve the corresponding crisp geometric averaging-weighted max-min model for the SCPLCC problem in relation to Equations (20) - (25).

Step10:Express RMCGP with both geometric averaging-weighted and no-penalty-weighted construction of the fuzzy optimization problem as expressed in Equations (27) and (30).

Step11:Express RMCGP with the geometric averaging-weighted and penalty-weighted construction of the fuzzy optimization problem, consistent with Equations (27) and (34).

Step 12:Solve the RMCGP with both geometric averaging-weighted and penalty-weighted GP constructions of the fuzzy optimization SCPLCC model problem, and compare the two GPs.

\section{Practical Example}

The company for which the SCPLCC problem model was tested is part of a multinational group [LED research \& development (R\&D) sector)] and manufactures electric light parts. External purchases annually accounted for over $75 \%$ of total costs. The company is a made-to-order firm, and its management intended to improve the efficiency of the purchasing process and re-consider the company's sourcing strategies. The management felt that evaluating and certifying there a vendor is essential to ensuring reductions in product inventory and the time to market. They had been encouraged to develop longer-term trust-based relationships with fewer vendors. Management appointed a team to recommend three or four suitable vendors. The team consisted of several managers from various departments such as purchasing, marketing, quality control, production, engineering and R\&D. The team members organize several meetings to create a profile of the contending vendors. They establish an initial set of three suppliers and evaluated them. An SCPLCC problem model was developed for the selection and quota allocations of the vendors under uncertain environments. The team considered the following four main objective functions; minimization of net cost, net rejections, the net late deliveries, and PLCC; these were all subject to a few practical constraints regarding the demand 
of the item, vendor capacity limitations, vendor budget allocations, and other factors. The price quoted ( $P_{i}$ in New Taiwan Dollars), the percentage of rejections $\left(R_{i}\right)$, the percentage of late deliveries $\left(\mathrm{L}_{\mathrm{i}}\right)$, the PLCC $\left(\mathrm{C}_{\mathrm{i}}\right)$, cost suppliers capacities $\left(\mathrm{U}_{\mathrm{i}}\right)$, supplier quota flexibility $\left(\mathrm{F}_{\mathrm{i}}\right.$ ) on a scale of 0 to1, percentage of rejections $\left(\mathrm{R}_{\mathrm{i}}\right)$ on a scale of 0 to 1 , and the budget allocations for the suppliers $\left(B_{i}\right)$ were considered. The three supplier profiles are presented in Table 3.

Table 3. Supplier source data for the problem.

\begin{tabular}{crrrrrrrr}
\hline Supplier no. & $\mathbf{P}_{\mathbf{i}} \mathbf{( \$ )}$ & $\mathbf{R}_{\mathbf{i}} \mathbf{( \% )}$ & \multicolumn{1}{c}{$\mathbf{L}_{\mathbf{i}} \mathbf{( \% )}$} & $\mathbf{C}_{\mathbf{i}} \mathbf{( \$ )}$ & $\mathbf{U}_{\mathbf{i}}$ (Units) & \multicolumn{1}{c}{$\mathbf{R}_{\mathbf{i}}$} & $\mathbf{F}_{\mathbf{i}}$ & \multicolumn{1}{c}{$\mathbf{B}_{\mathbf{i}} \mathbf{( \$ )}$} \\
\hline 1 & 3 & 0.05 & 0.04 & 1.92 & 5,000 & 0.88 & 0.02 & 25,000 \\
2 & 2 & 0.03 & 0.02 & 1.04 & 15,000 & 0.91 & 0.01 & 100,000 \\
3 & 6 & 0.02 & 0.08 & 3.94 & 6,000 & 0.97 & 0.06 & 35,000 \\
\hline
\end{tabular}

In this case demonstration, the linear MF was used to fuzzifying the right-hand side of the restrictions in the preceding SCPLCC model. The values of net cost, rejections, late deliveries and supplier capacity at the lowest and highest level of MF must be defined per Equations (11) and (12). The levels of uncertainty for all of the fuzzy parameters are assumed to be $10 \%$ of the deterministic model. The data sets for the values at the lowest and highest aspiration levels of the MFs are listed in Table 4 .

Table 4. Limiting values in the membership function for net cost, rejections, late deliveries, PLCC, vendor capacities and budget information.

\begin{tabular}{lcc}
\hline & (Min.) $\mu=1$ & (Max.) $\mu=0$ \\
\hline Net cost objective goal & 57,000 & 71,833 \\
Rejection objective goal & 413 & 521 \\
Late deliveries objective goal & 604 & 816 \\
Product life cycle cost objective goal & 10,000 & 90,000 \\
Capacity constraints & & \\
Supplier 1 & 5,000 & 5,500 \\
Supplier 2 & 15,000 & 16,500 \\
Supplier 3 & 6,000 & 6,600 \\
Budget constraints & & \\
Supplier 1 & 25,000 & 27,500 \\
Supplier 2 & 100,000 & 110,000 \\
Supplier 3 & 35,000 & 38,500 \\
\hline
\end{tabular}

\subsection{Application of WA Approach to the Numerical Example}

The example used was solving the problem by using Tiwari, Dharmar and Rao's WA approach [30]. Before starting the solution, the weights of four goals and six restrictions were determined using supertransitive approximation. Thus, we assumed that the following binary comparison matrix consists of obtain net cost, rejection of late deliveries, PLCC, Supplier 1 constraints, Supplier 2 constraints, and Supplier 3 constraints: 
$A=\left(\begin{array}{c}\text { Net cost } \\ \text { Rejection } \\ \text { Late deliveries } \\ \text { Product lifecycle cost } \\ \text { Vendor } 1 \text { capacity } \\ \text { Vendor } 2 \text { capacity } \\ \text { Vendor } 3 \text { capacity } \\ \text { Vendor } 1 \text { budget constraints } \\ \text { Vendor } 2 \text { budget constraints } \\ \text { Vendor } 3 \text { budget constraints }\end{array}\right)$

$\Rightarrow\left(\begin{array}{cccccccccc}1 & 6 & 4 & 9 & 3 & 4 & 9 & 9 & 8 & 2 \\ 1 / 6 & 1 & 1 / 2 & 3 & 1 / 3 & 1 / 3 & 2 & 4 & 5 & 1 / 4 \\ 1 / 4 & 2 & 1 & 4 & 1 / 2 & 1 / 2 & 3 & 5 & 6 & 1 / 3 \\ 1 / 9 & 1 / 3 & 1 / 4 & 1 & 1 / 5 & 1 / 2 & 2 & 3 & 3 & 1 / 6 \\ 1 / 3 & 3 & 2 & 5 & 1 & 1 & 4 & 6 & 7 & 1 / 2 \\ 1 / 4 & 3 & 2 & 5 & 1 & 1 & 4 & 6 & 7 & 1 / 2 \\ 1 / 9 & 1 / 2 & 1 / 3 & 2 & 1 / 4 & 1 / 4 & 1 & 3 & 4 & 1 / 5 \\ 1 / 9 & 1 / 4 & 1 / 5 & 1 / 2 & 1 / 6 & 1 / 6 & 1 / 3 & 1 & 2 & 1 / 8 \\ 1 / 8 & 1 / 5 & 1 / 6 & 1 / 3 & 1 / 7 & 1 / 7 & 1 / 4 & 1 / 2 & 1 & 1 / 9 \\ 1 / 2 & 4 & 3 & 6 & 2 & 2 & 5 & 8 & 9 & 1\end{array}\right)$

The supertransitive approximation method [32] is used to obtain the comparison matrix, and the following weights are obtained [9]: $w_{1}=0.2958, w_{2}=0.0579, w_{3}=0.0863$, $w_{4}=0.0365, w_{5}=0.1291, w_{6}=0.1254, w_{7}=0.0392, w_{8}=0.0199, w_{9}=0.0151, w_{10}=0.1949$.

\subsubsection{Solving the SCPLCC Example by Using the WA Approach}

For this SCPLCC example, the optimal quota allocations (i.e., purchasing order), supplier product capacity limitations, and budget restrictions among the different vendors were obtained using the Zimmermann WA method [33] as shown in Equations (13) - (19). This SCPLCC problem can then be reformulated as the following program:

$$
\begin{array}{ll}
\text { Maximize } & 0.2958 \lambda_{1}^{*}+0.0579 \lambda_{2}^{*}+0.0863 \lambda_{3}^{*}+0.0365 \lambda_{4}^{*}+0.1291 \lambda_{5}^{*} \\
& +0.1254 \lambda_{6}^{*}+0.0392 \lambda_{7}^{*}+0.0199 \lambda_{8}^{*}+0.0151 \lambda_{9}^{*}+0.1949 \lambda_{10}^{*}
\end{array}
$$

Subject to

$$
\begin{aligned}
& \lambda_{1}^{*} \leq\left(71833-\left(3 x_{1}+2 x_{2}+6 x_{3}\right)\right) /(71833-57000) \\
& \lambda_{2}^{*} \leq\left(521-\left(0.05 x_{1}+0.03 x_{2}+0.01 x_{3}\right)\right) /(521-413) \\
& \lambda_{3}^{*} \leq\left(816-\left(0.04 x_{1}+0.02 x_{2}+0.08 x_{3}\right) /(816-604)\right. \\
& \lambda_{4}^{*} \leq\left(90000-\left(1.92 x_{1}+1.04 x_{2}+3.94 x_{3}\right)\right) /(90000-10000) \\
& \mu_{1}^{*} \leq\left(71833-\left(3 x_{1}+2 x_{2}+6 x_{3}\right)\right) /(71833-57000) \\
& \mu_{2}^{*} \leq\left(521-\left(0.05 x_{1}+0.03 x_{2}+0.01 x_{3}\right)\right) /(521-413) \\
& \mu_{3}^{*} \leq\left(816-\left(0.04 x_{1}+0.02 x_{2}+0.08 x_{3}\right) /(816-604)\right.
\end{aligned}
$$




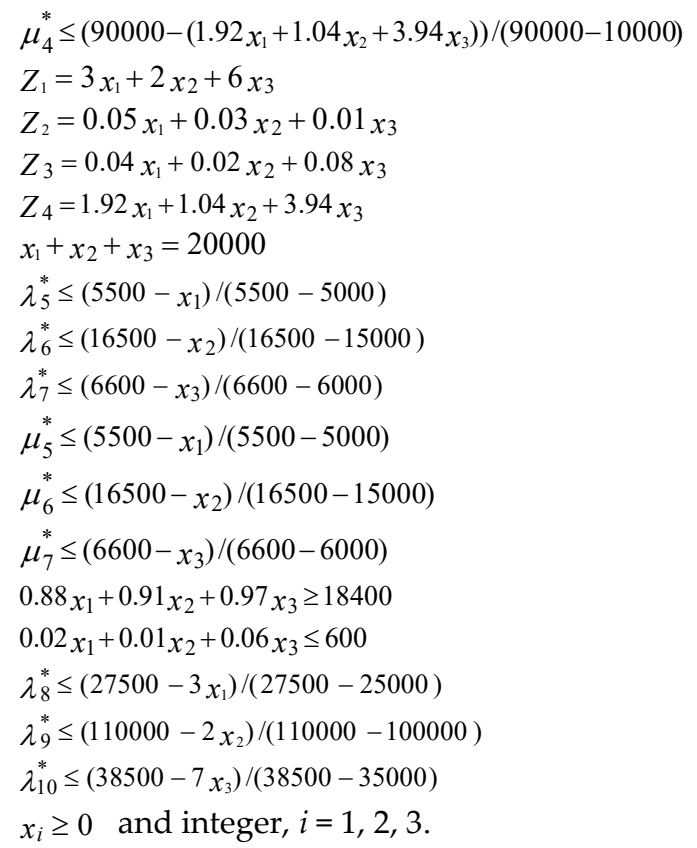

The numerical example of the SCPLCC problem was then solved using LINGO software (2002) [34], and the following solution was obtained:

$\begin{array}{lllll}x_{1}=240 & x_{2}=15,570 & x_{3}=4,190 & \mu_{1}=0 \quad \mu_{2}=0 \quad \mu_{3}=0 \\ \mu_{4}=0 & \mu_{5}=0 & \mu_{6}=0 & \mu_{7}=0.3066 \quad \mu_{8}=1 \\ \mu_{9}=1 & \mu_{10}=0.0011 & & & \\ z 1=57,000 & z_{2}=521 & z_{3}=656.20 & z_{4}=33,162.20 .\end{array}$

4.2.2. Solving the SCPLCC Example by Using the Weighted Max-Min Approach

For this illustrative SCPLCC example, the optimal quota allocations (i.e., purchasing order), supplier product capacity limitations, and budget constraints among the different supplier were obtained using the weighted max-min (Lin, 2004) approach as expressed in Equations (20)-(26). This SCPLCC problem can then be reformulated as the following program:

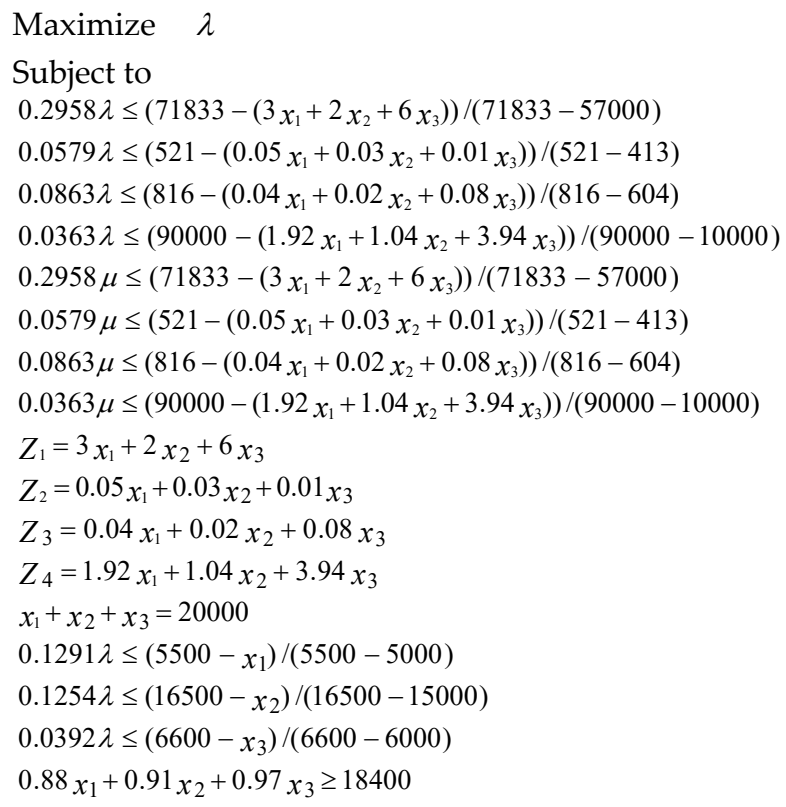




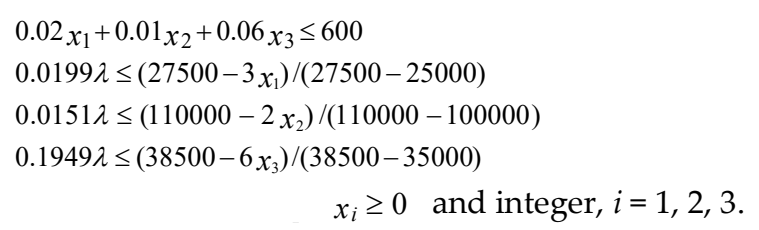

The numerical example of the SCPLCC problem was then solved using LINGO software (2002), and the following solution was obtained:

$\begin{array}{ccccc}x_{1}=0 & x_{2}=15,750 & x_{3}=4,250 & \lambda=0.9595 \quad \mu_{1}=0 \\ \mu_{2}=0 & \mu_{3}=0 & \mu_{4}=0 & \mu_{5}=0 \quad \mu_{6}=0 \\ \mu_{7}=0.3066 & \mu_{8}=1 & \mu_{9}=1 & \mu_{10}=0.0011 \\ z_{1}=57,000 & z_{2}=515 & z_{3}=655 & z_{4}=33,125 .\end{array}$

4.2.3. Solving the SCPLCC Example by Using the RMCGP Approach

We now consider a RMCGP problem with goals and constraints that cannot be solved by current GP methods. For this illustrative application, optimal quota allocations (i.e., purchasing order), supplier product capacity, and financial budget constraints among different suppliers were considered. This SCPLCC problem was then formulated as follows:

Main goals:

$\left(G_{1}\right) \quad 3 x_{1}+2 x_{2}+6 x_{3}=57,000$ (G1, MIN.) or 71,833 (G1, MAX.)

$\left(G_{2}\right) \quad 0.05 x_{1}+0.03 x_{2}+0.01 x_{3}=413\left(G_{2}\right.$, MIN. $)$ or $521\left(G_{2}\right.$, MAX.)

(G) $0.04 x_{1}+0.02 x_{2}+0.08 x_{3}=604\left(G_{3}\right.$, MIN. $)$ or $816\left(G_{3}\right.$, MAX.)

$\left(G_{4}\right) 1.92 x_{1}+1.04 x_{2}+3.94 x_{3}=10,000\left(G_{4, \text { MIN. }}\right)$ or $90,000\left(G_{4, \text { MAX. }}\right)$

Capacity constraints:

$\left(G_{5}\right) \quad x_{1}=5,000\left(G_{5}, \mathrm{MIN}\right.$.)or $5,500\left(G_{5}, \mathrm{MAX}.\right)\left(\mathrm{X}_{1}\right.$, Supplier 1 product capacity)

$\left(G_{6}\right) \quad x_{2}=15,000\left(G_{6}, \mathrm{MIN}\right.$.) or 165,000(G6, MAX.) (X2, Supplier 2 product capacity)

$\left(G_{7}\right) x_{3}=6,000\left(G 7\right.$, MIN.) or $165,000\left(G 7\right.$, MAX.) $\left(X_{3}\right.$, Supplier 3 product capacity)

$x_{1}+x_{2}+x_{3}=20,000 \quad$ (Total demand constraint)

Budget constraints:

$\left(G_{8}\right) \quad 3 x_{1}=25,000\left(G_{8}\right.$, MIN.) or 27,500 (G8, MAX.) (X $\mathrm{X}_{1}$, Vendor 1 budget constraint)

$\left(G_{9}\right) 2 x_{2}=100,000$ (G9, MIN.)or 110,000 (G9, MAX.) $\left(\mathrm{X}_{2}\right.$, Vendor 2 budget constraint)

$\left(G_{10}\right) 6 x_{3}=35,000$ ( $G_{10}$, MIN.)or 110,000 (G10, MAX.) (X3, Vendor 3 budget constraint)

Through the RMCGP no-penalty weighted method [31] with a geometric averaging-weighted approach $[9,31]$, this SCPLCC Problem was then expressed as the following program:

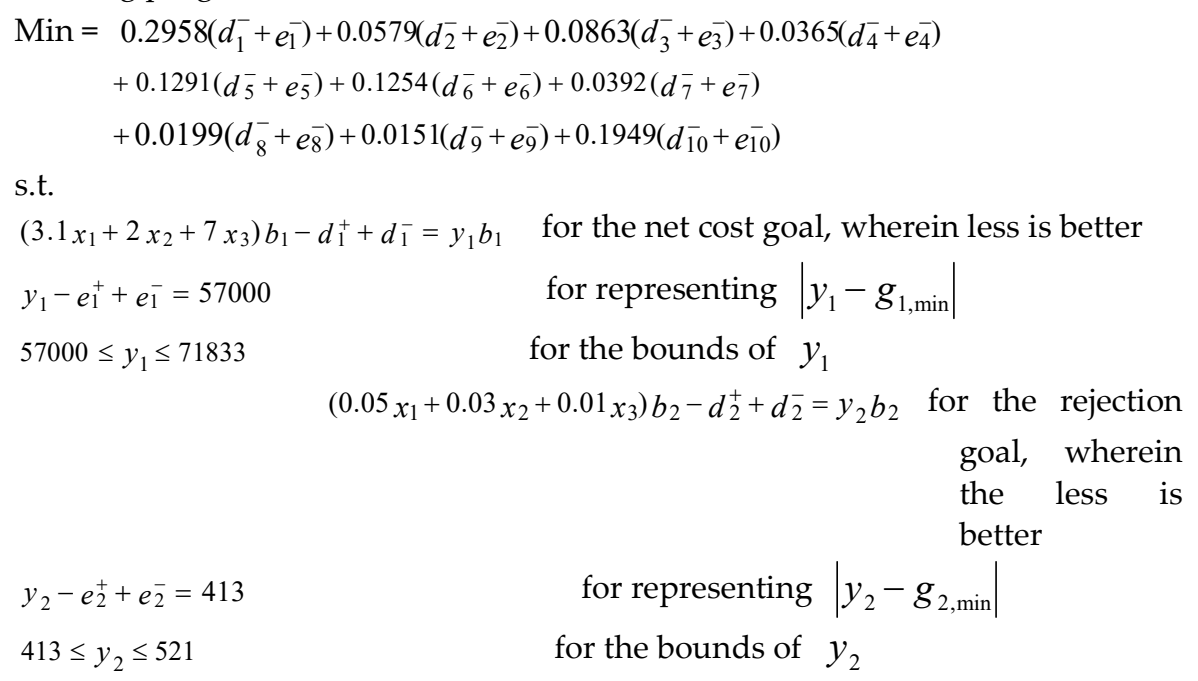




$$
\begin{aligned}
& \left(0.04 x_{1}+0.02 x_{2}+0.08 x_{3}\right) b_{3}-d_{3}^{+}+d_{3}^{-}=y_{3} b_{3} \quad \text { for } \quad \text { the late } \\
& \text { deliveries goal, } \\
& \text { wherein less is } \\
& \text { better } \\
& y_{3}-e_{3}^{+}+e_{3}^{-}=604 \\
& \text { for representing }\left|y_{3}-g_{3, \min }\right| \\
& 604 \leq y_{3} \leq 816 \quad \text { for the bounds of } y_{3} \\
& \left(1.92 x_{1}+1.04 x_{2}+3.94 x_{3}\right) b_{4}-d_{4}^{+}+d_{4}^{-}=y_{4} b_{4} \text { for the PLCC goal, wherein less is better } \\
& y_{4}-e_{4}^{+}+e_{4}^{-}=10000 \quad \text { for representing }\left|y_{4}-g_{4, \min }\right| \\
& 1000 \leq y_{4} \leq 90000 \quad \text { for the bounds of } y_{4} \\
& x_{1} b_{5}-d_{5}^{+}+d_{5}{ }_{5}=y_{5} b_{5} \quad \text { for the supplier } 1 \\
& \text { capacity constraint } \\
& \text { goal, wherein less } \\
& y_{5}-e_{5}^{+}+e_{5}^{-}=5000 \\
& \text { for representing }\left|y_{5}-g_{5, \min }\right| \\
& 5000 \leq y_{5} \leq 5500 \\
& x_{2} b_{6}-d_{6}^{+}+d \overline{6}=y_{6} b_{6} \\
& \text { for the bounds of } y_{5} \\
& \text { for the supplier } 2 \text { capacity constraint } \\
& \text { goal, wherein less } \\
& \text { is better } \\
& y_{6}-e_{6}^{+}+e_{6}^{-}=15000 \\
& 15000 \leq y_{6} \leq 16500 \\
& x_{3} b_{7}-d_{7}^{+}+d_{7}^{-}=y_{7} b_{7} \\
& y_{7}-e_{7}^{+}+e_{7}^{\overline{-}}=6000 \\
& 6000 \leq y_{7} \leq 6600 \\
& 3 x_{1} b_{8}-d_{8}^{+}+d_{8}^{-}=y_{8} b_{8} \\
& y_{8}-e_{8}^{+}+e_{8}^{-}=25000 \\
& 25000 \leq y_{8} \leq 27500 \\
& 2 x_{2} b_{9}-d_{9}^{+}+d_{9}^{-}=y_{9} b_{9} \\
& y_{9}-e_{9}^{+}+e_{9}^{-}=100000 \\
& 100000 \leq y_{9} \leq 110000 \\
& 6 x_{3} b_{10}-d_{10}^{+}+d_{10}^{-}=y_{10} b_{10} \\
& y_{10}-e_{10}^{+}+e_{10}^{-}=35000 \\
& 35000 \leq y_{9} \leq 38500 \\
& \text { for representing }\left|y_{6}-g_{6, \min }\right| \\
& \text { for the bounds of } y_{6} \\
& \text { for supplier } 3 \text { capacity constraint goal, } \\
& \text { wherein less is better } \\
& \text { for representing }\left|y_{7}-g_{7, \min }\right| \\
& \text { for the bounds of } y_{7} \\
& \text { for the supplier } 1 \text { budget constraint goal, } \\
& \text { wherein less is better } \\
& \text { for representing }\left|y_{8}-g_{8, \min }\right| \\
& \text { for the bounds of } y_{8} \\
& \text { for the supplier } 2 \text { budget constraint goal, } \\
& \text { wherein less is better } \\
& \text { for representing }\left|y_{9}-g_{9, \min }\right| \\
& \text { for the bounds of } y_{9} \\
& \text { for the supplier } 3 \text { budget constraint goal, } \\
& \text { wherein less is } \\
& \text { better } \\
& \text { for representing }\left|y_{10}-g_{10, \min }\right| \\
& \text { for the bounds of } y_{10}
\end{aligned}
$$


$Z_{1}=3 x_{1}+2 x_{2}+6 x_{3}$

$Z_{2}=0.05 x_{1}+0.03 x_{2}+0.01 x_{3}$

$Z_{3}=0.04 x_{1}+0.02 x_{2}+0.08 x_{3}$

$Z_{4}=1.92 x_{1}+1.04 x_{2}+3.94 x_{3}$

$x_{1}+x_{2}+x_{3}=20000$

$0.88 x_{1}+0.91 x_{2}+0.97 x_{3} \geq 18400$

$0.02 x_{1}+0.01_{x_{2}}+0.06 x_{3} \leq 600$

$x_{i} \geq 0$ and $i=1,2,3$.

$d_{i}^{+}, d_{i}^{-}, e_{i}^{+}, e_{i}^{-} \geq 0 \quad(i=1,2 \ldots 10)$

$b_{i} \geq 0 \quad(i=1,2, \ldots, 10)$ are binary variable.

that the

lower-bound goal is achieved) and either the rejection goal or the late delivery goal is achieved

The numerical example of the SCPLCC problem was then solved using LINGO software [34], and the following solution was obtained:

$$
\begin{array}{lccccrr}
x_{1}=5,000 & x_{2}=9,166.67 & x_{3}=5833.33 & \mathrm{y}_{1}=57,000 & \mathrm{y}_{2}=410 & \mathrm{y}_{3}=604 \\
\mathrm{y}_{4}=10,000 & \mathrm{y}_{5}=5,000 & \mathrm{y}_{6}=15,000 & \mathrm{y}_{7}=6,000 & \mathrm{y}_{8}=25,000 \\
\mathrm{y}_{9}=100,000 & \mathrm{y}_{10}=35,000 & b_{1}=1 & b_{2}=0 & b_{3}=0 & \\
b_{4}=0 & b_{5}=1 & b_{6}=0 & b_{8}=0 & & \\
b_{9}=0 & b_{10}=0 & & & & \\
z_{1}=68,383.33 & z_{2}=583.33 & z_{3}=850 & z_{4}=42,116.67 &
\end{array}
$$

Thus, the RMCGP method with a geometric averaging-weighted (no-penalty weighted) approach could solve the SCPLCC problem with minimization of the net cost, rejection, late delivery, and PLCC as the goals.

4.2.4. Solving the SCPLCC Example by Using RMCGP with Geometric Averaging-Weighted and Penalty-Weighted Methods

First, in this SCPLCC example, the optimal quota allocations (i.e., purchasing order), supplier product capacity limitations and budget constraints among the suppliers were obtained using the RMCGP method with a penalty-weighted approach, as expressed in €Equations (27) and (30). This SCPLCC problem can then be reformulated in the following program:

$\operatorname{Min}=0.2958\left(5 d_{1}^{+}+d_{1}^{-}+e_{1}^{-}\right)+0.0579\left(4 d_{2}^{+}+d_{2}^{-}+e_{2}^{-}\right)+0.0863\left(3 d_{3}^{+}+d_{3}^{-}+e_{3}^{-}\right)$
$+0.0365\left(2 d_{4}^{+}+d_{4}^{-}+e_{4}^{-}\right)+0.1291\left(d_{5}^{-}+e_{5}^{-}\right)+0.1254\left(d_{6}^{-}+e_{6}^{-}\right)$
$+0.0392\left(d_{7}^{-}+e_{7}^{\overline{7}}\right)+0.0199\left(d_{8}^{-}+e_{8}^{-}\right)+0.0151\left(d_{9}^{-}+e_{9}^{-}\right)+0.1949\left(d_{10}^{-}+e_{10}^{-}\right)$

s.t.

$$
\begin{aligned}
& \left(3.1 x_{1}+2 x_{2}+7 x_{3}\right) b_{1}-d_{1}^{+}+d_{1}^{-}=y_{1} b_{1} \\
& y_{1}-e_{1}^{+}+e_{1}^{-}=57000 \\
& 57000 \leq y_{1} \leq 71833 \\
& \quad\left(0.05 x_{1}+0.03 x_{2}+0.01 x_{3}\right) b_{2}-d_{2}^{+}+d_{2}^{-}=y_{2} b_{2} \\
& y_{2}-e_{2}^{+}+e_{2}^{-}=413 \\
& 413 \leq y_{2} \leq 521 \\
& \left(0.04 x_{1}+0.02 x_{2}+0.08 x_{3}\right) b_{3}-d_{3}^{+}+d_{3}^{-}=y_{3} b_{3} \\
& y_{3}-e_{3}^{+}+e_{3}^{-}=604 \\
& 604 \leq y_{3} \leq 816 \\
& \left(1.92 x_{1}+1.04 x_{2}+3.94 x_{3}\right) b_{4}-d_{4}^{+}+d_{4}^{-}=y_{4} b_{4} \\
& y_{4}-e_{4}^{+}+e_{4}^{-}=10000
\end{aligned}
$$




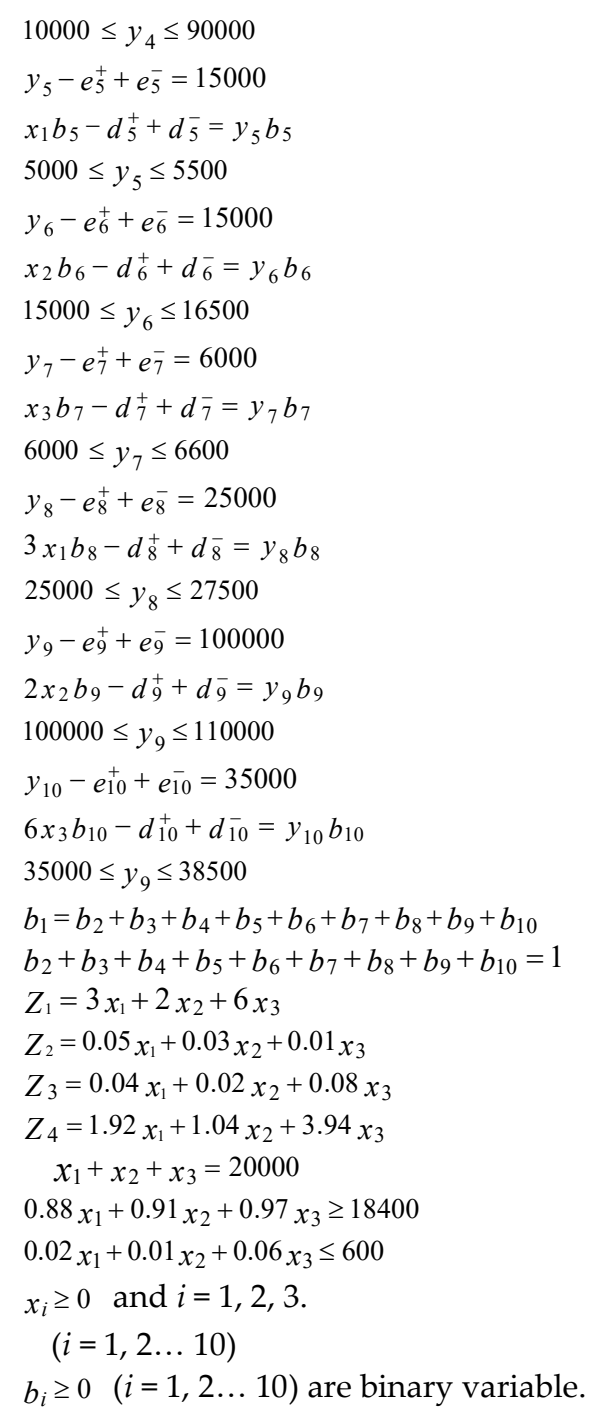

The numerical example of the SCPLCC problem was then solved using LINGO software [34], and the following solution was obtained:

$\begin{array}{llllll}x_{1}=0 & x_{2}=15,750 & x_{3}=4,250 & \mathrm{y}_{1}=57,000 & \mathrm{y}_{2}=410 & \mathrm{y}_{3}=604 \\ \mathrm{y}_{4}=10,000 & \mathrm{y}_{5}=5,000 & \mathrm{y}_{6}=15,000 & \mathrm{y}_{7}=6,000 & \mathrm{y}_{8}=25,000 & \mathrm{y}_{9}=100,000 \\ \mathrm{y} 10=35,000 & b_{1}=1 & b_{2}=0 & b_{3}=0 & b_{4}=0 & b_{5}=0 \\ b_{6}=1 & b_{8}=0 & b_{9}=0 & b_{10}=0 & & \\ z_{1}=57,000 & z_{2}=515 & z_{3}=655 & z_{4}=33,125 . & & \end{array}$

Here, the RMCGP method with the geometric averaging-weighted and penalty-weighted approaches could be suitable for solving the SCPLCC problem with the goals of minimizing the net cost, rejection, late delivery, and PLCC goals.

\subsubsection{RMCGP with Averaging-Weighting Penalty-Weighted and Weighted linear Goal} Programming

In order to verify RMCGP SCPLCC model problem, we modify RMCGP SCPLCC model with averaging weighted penalty-weighted linear goal programming (WLGP). The objectives function is expressed mathematically in the following Equation [13]:

$\mathrm{MIN}=$

$\frac{\theta_{1}}{T_{1}} d n_{1}^{-}+\frac{\theta_{2}}{T_{2}} d p_{2}^{+}+\frac{\theta_{3}}{T_{3}} d n_{3}^{-}+\frac{\theta_{4}}{T_{4}} d n_{4}^{-}+\frac{\theta_{5}}{T_{5}} d p_{5}^{+}+\frac{\theta_{6}}{T_{6}} d p_{6}^{+}+\frac{\theta_{7}}{T_{7}} d n_{7}^{-}+\frac{\theta_{8}}{T_{8}} d n_{8}^{+}+\frac{\theta_{9}}{T_{9}} d n_{9}^{-}+\frac{\theta_{10}}{T_{10}} d n_{10}^{-}$

Where: 
$\theta_{i}=i^{\text {th }}$ the geometric averaging weighting; $i=1,2,3 \ldots 10$,

$\theta_{1}=0.2958 ; \theta_{2}=0.0579 ; \theta_{3}=0.0863 ; \theta_{4}=0.0365 ; \theta_{5}=0.1291 ; \theta_{6}=0.1254 ; \theta_{7}=0.0392$;

$\theta_{8}=0.0199 ; \theta_{9}=0.0151 ;$ and $\theta_{10}=0.1949$.

$T_{i}={ }_{i}^{\text {th }}$ goal's normalization constant, $i=1,2,3 \ldots 10$,

$T_{1}=57,000$ (total net cost objective goal)

$T_{2}=515$ (total rejection objective goal)

$T_{3}=655$ (total late deliveries objective goal)

$T_{4}=33,125$ (total PLCC objective goal)

$T_{5}=5000$ (total Supplier 1 capacity constraints goal)

$T_{6}=15000$ (total Supplier 2 capacity constraints goal)

$T_{7}=6000$ (total Supplier 3 capacity constraints goal)

$T_{8}=25000$ (total Supplier 1 budget constraints goal)

$T_{9}=100,000$ (total Supplier 2 budget constraints goal)

$T_{10}=35,000$ (total Supplier 3 budget constraints goal)

Subsequently, the numerical example of the SCPLCC problem was then solved using LINGO software [41], and the following solution was obtained:

$\mathrm{x}_{1}=1034.48 \quad \mathrm{x}_{2}=15,000 \quad \mathrm{x}_{3}=3965.51 \quad \mathrm{y}_{1}=57,000 \quad \mathrm{y}_{2}=410 \quad \mathrm{y}_{3}=604 \quad \mathrm{y}_{4}=10,000$

$\mathrm{y}_{5}=5,000 \quad \mathrm{y}_{6}=15,000 \quad \mathrm{y}_{7}=6,000 \quad \mathrm{y}_{8}=25,000 \quad \mathrm{y}_{9}=100,000 \quad \mathrm{y}_{10}=35,000$

$\mathrm{Z}_{1}=56,896.55 \quad \mathrm{Z}_{2}=541.37 \quad \mathrm{z}_{3}=658.62 \quad \mathrm{Z}_{4}=33,2107$.

Thus, a RMCGP SCPLCC model with averaging weighted penalty-weighted goal programming and with a weighted linear GP solution result should have similar obtained values. The model indicated that Supplier 2 was suitable.

\subsection{Summarize Results of the all Types GP Approaches}

After solving the SCPLCC problem, we summarized the results of all GP approaches, as presented in Table 5 .

Table 5. Results of all GP approaches.

\begin{tabular}{|c|c|c|c|c|c|}
\hline Approach & $\begin{array}{c}\text { Zimmermann's } \\
\text { additive } \\
\text { weighted(FMOLP) }\end{array}$ & \begin{tabular}{l}
\multicolumn{1}{c}{ Lin's } \\
weighted \\
max-min \\
(FMOLP)
\end{tabular} & $\begin{array}{l}\text { RMCGP with } \\
\text { averaging } \\
\text { weighted NO } \\
\text { penalty- } \\
\text { weighted }\end{array}$ & $\begin{array}{l}\text { RMCGP } \\
\text { with } \\
\text { geometric } \\
\text { averaging } \\
\text { weighted } \\
\text { penalty- } \\
\text { weighted }\end{array}$ & $\begin{array}{l}\text { RMCGP with } \\
\text { geometric } \\
\text { averaging } \\
\text { weighted } \\
\text { penalty- } \\
\text { weighted and } \\
\text { WLGP }\end{array}$ \\
\hline \multicolumn{6}{|l|}{ Objective } \\
\hline $\begin{array}{c}\text { Net cost } \\
\text { z1 }\end{array}$ & 57,000 & 57,000 & $68,383.33$ & 57,000 & $56,896.55$ \\
\hline $\begin{array}{c}\text { Rejection } \\
\text { z2 }\end{array}$ & 521 & 515 & 583 & 515 & 541.37 \\
\hline $\begin{array}{c}\text { Late deliveries } \\
\text { z3 } \\
\end{array}$ & 656 & 655 & 850 & 655 & 658.62 \\
\hline $\begin{array}{l}\text { Product Life } \\
\text { cycle cost z4 }\end{array}$ & 33,162 & 33,125 & $42,116.67$ & 33,125 & 33210 \\
\hline $\begin{array}{l}\text { Order quantity } \\
\text { x1 }\end{array}$ & 240 & 0 & 15,000 & 0 & $1,034.48$ \\
\hline $\begin{array}{l}\text { Order quantity } \\
x 2\end{array}$ & 15,570 & 15,750 & $9,166.67$ & 15,750 & 15,000 \\
\hline $\begin{array}{l}\text { Order quantity } \\
\text { x3 }\end{array}$ & 4,190 & 4,250 & $5,833.33$ & 4,250 & $3,965.51$ \\
\hline \multicolumn{6}{|l|}{$\begin{array}{l}\text { Capacity } \\
\text { restrictions }\end{array}$} \\
\hline Supplier 1 & $\begin{array}{l}5,500 \\
(\max .)\end{array}$ & 5,500 & $5,000\left(\mathrm{y}_{5}\right)$ & $\begin{array}{c}5,000 \\
\left(\mathrm{y}_{5}\right) \\
\end{array}$ & $\begin{array}{c}5,000 \\
\left(\mathrm{y}_{5}\right) \\
\end{array}$ \\
\hline
\end{tabular}




\begin{tabular}{|c|c|c|c|c|c|}
\hline Supplier 2 & 1,6500 & 16,500 & $15,000\left(\mathrm{y}_{6}\right)$ & $\begin{array}{c}15,000 \\
\left(\mathrm{y}_{6}\right)\end{array}$ & $\begin{array}{c}15,000 \\
\left(\mathrm{y}^{6}\right) \\
\end{array}$ \\
\hline Supplier 3 & 6,600 & 6,600 & $6,000(y 7)$ & $\begin{array}{c}6,000 \\
(\mathrm{y} 7) \\
\end{array}$ & $\begin{array}{c}6,000 \\
(\mathrm{y} 7) \\
\end{array}$ \\
\hline \multicolumn{6}{|l|}{$\begin{array}{c}\text { Budget } \\
\text { restrictions }\end{array}$} \\
\hline Supplier 1 & 27,500 & 27,500 & $25,000(\mathrm{y} 8)$ & $\begin{array}{c}25,000 \\
(\mathrm{y} 8) \\
\end{array}$ & $\begin{array}{c}25,000(\mathrm{y} 8 \\
)\end{array}$ \\
\hline Supplier 2 & 110,000 & $\begin{array}{c}110,00 \\
0\end{array}$ & $\begin{array}{c}100,000 \\
\left(\mathrm{y}_{9}\right)\end{array}$ & $\begin{array}{c}100,00 \\
0 \\
(\mathrm{y} 9)\end{array}$ & $\begin{array}{c}100,000 \\
\left(\mathrm{y}_{9}\right)\end{array}$ \\
\hline Supplier 3 & 38,500 & 38,500 & $\begin{array}{c}35,000 \\
(\mathrm{y} 10) \\
\end{array}$ & $\begin{array}{c}35,000 \\
(\mathrm{y} 10)\end{array}$ & $\begin{array}{c}35,000 \\
(\mathrm{y} 10) \\
\end{array}$ \\
\hline
\end{tabular}

\subsection{Discussion of the Two Approaches' Results}

After solving the SCPLCC problem, we found that Lin's [29] weighted max-min approach and the RCMCGP method with geometric averaging and penalty-weighted approaches produced the same solution.

Regarding the RMCGPs with a geometric-averaging-weighted (no-penalty-weighted restrictions) approaches, the solution results were $x_{1}=5,000$ (due to an absence of penalty-weighed constraints), $b_{1}=1$ and $b_{5}=1$, and the lower bound Supplier 1 order quantity was 5,000 $\left(x_{1}=5,000\right)$ (Table 5).

Regarding the others RMCGP with geometric averaging-weighted and penalty-weighted approaches, the solution results were $b_{1}=1$ and $b_{6}=1$, and the upper bound Supplier 2 order quantity was over 15,000, $\left(x_{2}=15,750\right)$. To ensure that the net cost rejection or late delivery goal is met, zero should be obtained (e.g., $b_{1}=1, b_{6}=1$, and the $b_{i}$ auxiliary constraints should be used when adjusting the purchasing quantity (Table 5).

In order to compare the verification and increase the accuracy, use RMCGP with geometric averaging weighted penalty weighted and a WLGP model to prove the correctness Thus, RMCGP SCPLCC models with averaging weighted penalty-weighted goal programming and with a weighted linear GP solution result have obtained the same results (Table 5 the fifth model).

\section{Conclusions and Managerial Implications}

\subsection{Conclusions}

SC is one of the most important activities in SCM. Because many factors (i.e., net cost, rejection, late delivery, PLCC SC strategy in a high-tech company, achieving only one objective is insufficient for reducing the PLCC. In other studies, SC models for solving this SCPLCC problem have seldom examined. In the present study, we first attempted to solve the SCPLCC problem with two approaches, both of which considered geometric-averaging-weighted methods. The solution results for the two approaches=presented in this paper should be useful for deter mining vendors quotas in SCM when the three capacities and budget constraints of each vendor are uncertain (i.e., given a minimum. or maximum. bound). The first approach, which used the uncertainty of the fuzzy model, used a linear MF, and the entire formulation was solved through a fuzzy multiobjective programming approach. The SCPLCC problem was then transformed through weighted max-min and additive-weighted MOLP and its equivalent crisp single-objective LP programming. The second approach, which used geometric averaging-weighted RMCGP and a penalty-weighted approach emphasized supplier upgrades, such as increased product quality, reduced PLCC, and guided the relationships between goals in the multiple objective problems. 


\subsection{Managerial Applications}

Our study has of the following managerial implications:

(i) The SCPLCC problem can easily be solved with commercially available LP software such as LINDO and LINGO.

(ii) Our solution of the SCPLCC problem is more comprehensive than LP, and GP, and other deterministic methods that are used for information vagueness, and our solution is captured in two approaches. The SCPLCC problem is transformed into a weighted max-min fuzzy programming model that yields less computational complexity and makes the application of fuzzy methodology more understandable [8].

(iii) In real-world situations of designing SCM, the designer need not provide deterministic values of system parameters, such as product capacity and constraints.

(iv) In the RMCGP approach [31], auxiliary constraints can guide the relationships between goals in the multiple objective problems. For the SCPLCC problem example, auxiliary constraints $\left(b_{\mathrm{i}}\right)$-can force achieved goals (e.g., can adjust vendor order quota allocation). RMCGP problem exist within many managerial DM problems. We modified Chang [31] proposed RMCGP with weighted GP to solve the SCPLCC problem by using multiplicative terms of binary variables to account for the multiple target levels. Under some conditions, DMs may want to make a decision toward a goal that can be achieved from a particular aspiration level (i.e., one goal mapping many aspiration levels) [35]. These RMCGP problems exist in many managerial decision-making situations. Little [36] suggested that the model developed in the present paper here satisfies the main demands formulated for operational models and argued that a truly useful model must be simple, robust, easily controllable, adaptive, complete on important SCPLCC issues, and easily communicated. Our SCPLCC problem model appeared to satisfy the first four qualifications in particular [13].

We demonstrated our SCPLCC based PLCC concept model by using a real-world example LED company in Taiwan. In practice, high-tech companies can easily apply our example to select supplier in a fuzzy environment by using the two GP approaches, because precise knowledge of all the parameters is not required. In real cases, the two methods for solving SCPLCC problems can help DMs determine the appropriate prioritization of suppler and allow purchasing managers to manage supply chain performance on the basis of net cost, rejection, late delivery, and PLCC goals. Company managers can easily use the two approaches of the SCPLCC problem model with different parameters to solve SCPLCC problems.

\subsection{Limitations}

To eliminate the drawbacks of the two of GP approaches and obtain precise outcomes, we compared the models with the RMCGP and weighted GP approaches to verify the SCPLCC problem. If DMs use a new RMCGP method combination multi-criteria decision-making approach, it can be a different result in unclear situation.

\subsection{Future Directions}

Our SCPLCC models can integrate other GP modes, such as De Novo programming and other multicriteria decision-making approaches such as rough sets $[37,38]$ or neutrosophic sets [39], to solve SCPLCC problems with a multisupplier situation.

Author Contributions: Conceptualization, T.Y.J.; formal analysis, T.C.S and T.Y.J; writing-original draft preparation, T.Y.J and T.C.S; writing-review and editing, T.C.S and T.Y.J.; planning all works in the study, L.H.S and supervision, L.Y.S.

Funding: This research received no external funding. 
Conflicts of Interest: The authors declare no conflict of interest.

\section{References}

1. Choi, J.; Bai, J.; Geunes, H. Manufacturing delivery performance for supply chain management. Math. Compu. Model. 2007, 45, 11-20.

2. Li, G.; Yamaguchi, M.; Nagai, M. A grey-based decision-making approach to the supplier selection problem, Math. Comp. Model. 2007, 46, 573-581.

3. Michaels, R.; Kumar A.; Samu, S. Activity-specific role stress in purchasing Int. J. Purch. Mater. Manag. 1995, 31, 11-19.

4. Patton, W. E. Individual and joint decision-making in industrial vendor selection. J. Bus. Res. 1997, 38, 115-122.

5. Wang, G.; Hung, S. H.; Dismukes, J. P. Product-driven supply chain selection using integrated multi-criteria decision-making methodology. Int. J. Prod.Econ. 2004, 91, 1-15.

6. Vidrová Z. Supply chain management in the aspect of globalization, SHS Web of Conferences, 2020.74,04031.

7. Amid A.; Ghodsypour S.H. and O'Brien, C. A. Weighted max-min model for fuzzy multi-objective supplier selection in a supply chain, Int. J. Prod. Econ. 2010, 131(1), 139-145.

8. Kumar, M.; Vrat, P.; Shankar, R. A fuzzy goal programming approach for vendor selection problem in a supply chain. Int. J. Prod. Econo. 2006, 101, 273-285.

9. Kagnicioglu, C. H. A fuzzy multi-objective programming approach for supplier selection in a supply chain, The Bus. Rev. Cambridge. 2006, 6(1), 107-115.

10. Shen, C.W.; Peng, Y.T.; Tu, C.S. Considering Product Life Cycle Cost Purchasing Strategy for Solving Vendor Selection Problems. Sustainability 2019, 11, 3739.

11. Dickson, G.W. An analysis of vendor selection systems and decisions. J. Purch. 1966, 2(1), 5-17.

12. Wind, Y.; Robinson, P.J. The determinants of vendor selection: the evaluation function approach. J. Pur. Mater. Manag.1968, 29-41.

13. Mo'Ath, A.L., Ahmad K. J., Mohd H. Z.; Afifi M. D. Weighted linear goal programming approach for solving budgetary manufacturing process, Far East j. math. Sci., May 2017.

14. Umarusman N. Solution proposal for supplier selection: problem an application in agricultural machinery sector with global criterion method, Dokuz Eylul Universitesi Iktisadi ve Idari Bilimler Dergisi 2018, 33(1), 353-368

15. Budzinski M.; Sisca M. Thrän D. Consequential LCA and LCC using linear programming: an illustrative example of biorefineries. Int. J. Life Cycle Assess. 2019, 24(2), 2191-2205.

16. Ojo, O. O.; Farayibi, P. K.; Akinnuli, B. O. Modified goal programming model for limited available budget alocation for equipment procurement under inflation condition. Adv. Res., 2020.21(4), 25-35.

17. Hocine, A.; Zhuang, Z.Y.; Kouaissah, N.; Li, D C. Weighted-additive fuzzy multi-choice goal programming (WA-FMCGP) for Supporting Renewable Energy Site Selection Decisions. Eur. J. Oper. Res. 2020, 285, 642-652.

18. Hardy, C.; Bhakoo V.; Maguire, S.A new methodology for supply chain management: discourse analysis and its potential for theoretical advancement. J. Supply Chain Manag. 2020, 56(2), 19-35.

19. Al-Husain, R.; Khorramshahgol, R. Incorporating analytical hierarchy process and goal programming to design responsive and efficient supply chains. Oper. Res. Pers. 2020, 7, 100149.

20. Giri, B. C.; Dey, S. Game theoretic models for a closed-loop supply chain with stochastic demand and backup sup plier under dual channel recycling. Decis. Mak., Appl. Manag. Eng., 2020. 3(1), 108-125.

21. Samanta, B., \& Giri, B. C. A two-echelon supply chain model with price and warranty dependent demand and pro-rata warranty policy under cost sharing contract. Decis. Mak., Appl. Manag. Eng., 2021, 4(2), 47-75.

22. Bahareh, S. O..; Kaveh, K.D..; Peiman, G. Solving a supply chain problem using two approaches of fuzzy goal programming based on TOPSIS and fuzzy preference relations. Int. J. Ind. Syst. Eng. 2021,13(2),27-48.

23. Nasr, A. K., Tavana M.; Alavi, B.; Mina, H. A novel fuzzy multi-objective circular supplier selection and order allocation model for sustainable closed-loop supply chains. J. Clean. Prod., 2021, 287, 124994.

24. Kumar, L.; Jain, P. K.; Sharma, A. K. A fuzzy goal programme - based sustainable Greenfield supply network design for tyre retreading industry, Int. J. Adv. Manuf. Technol., 2020, 108(4),1-26.

25. Zimmermann, H. J. Fuzzy programming and linear programming with several objective functions. Fuzzy Sets Syst. 1987, 1, 45-56.

26. Bellman, R.E.; Zadeh, L.A. Decision making in a fuzzy environment. Manag. Sci. 1970, 17, 141-164. 
27. Lee, H. I.; Kang H. Y.; Chang, C.T. Fuzzy multiple goal programming applied to TFT-LCD supplier selection by downstream manufacturers. Exp. Syst. Appl. 2009, 36, 6318-6325.

28. Liao, C. N.; Kao, H. P. Supplier selection model using Taguchi loss fuction, analytical hierarchy process and multi-choice goal programming. Comp. Indu. Eng. 2010, 58, 571-577.

29. Lin, C.C. A weighted max-min model for fuzzy goal programming, Fuzzy Sets Syst. 2004,142, 407-420.

30. Tiwari, R.N. Dharmar, S.; Rao, J. R. Fuzzy goal programming - an additive model. Fuzzy Sets Syst. 1987, 24, 27-34.

31. Chang, C. T. Revised multi-choice goal programming. Appl. math. Model. 2008, 32, 2587-2595.

32. Narsimhan, R. An analytical approach to supplier selection. J. Purch. Mater. Manag. 1983, 27-32.

33. Zimmermann, H. J. Fuzzy programming and linear programming with serveral objective functions. Fuzzy Sets Syst. 1987, 1, 45-56.

34. Schrage, L. LINGO Release 8.0; LINGO System Inc.: Chicago, IL.60622, USA, 2002.

35. Chang, C. T. Multi-choice goal programming. Omega, 2007, 35, 389-396.

36. Little, D. C. Models and manager: the concept of a decision calculus. Manag. Sci. 1970, 16(8), 466-485.

37. Stević, Ž.; Tanackov I.; Vasiljević, M.; Rikalović, A.Supplier evaluation criteria: AHP Rough approach. October Conference: XVII International Scientific Conference on Industrial Systems (IS'17), At Novi Sad, Serbia, 2017, October $4-6$.

38. Stanković, M., Gladović, P., Popović, V. Determining the importance of the criteria of traffic accessibility using fuzzy AHP and rough AHP method. Decis. Mak. Appl. Manag. Eng., 2019, 2(1), 86 - 104.

39. Bausys, R.; Zavadskas, E. K.; Kaklauskas, A. Application of neutrosophic set to multicriteria decision making by COPRAS. Econ. Comput. Econ. Cybern Stud. Res. 2015, 49(2): 9 - 106. 